\title{
PACIENTE PELA SEGURANÇA DO PACIENTE: EM BUSCA DE AUTONOMIA
}

Elaine Ribeiro Rossi (1), Eloisa Gabriela Linke (2) e Tiago Calvis Siebert (3).

\section{INTRODUÇÃO}

Segurança do Paciente é um tema de estudo e pesquisa onde busca-se aprimorar a atenção à saúde. A partir disso, o programa Paciente pela Segurança do Paciente, criado pela OMS, estimula a melhora na segurança tendo os pacientes como protagonistas do cuidado à saúde, parceiros nos esforços para prevenir erros evitáveis em saúde (OMS, 2006). Assim, torna-se também responsabilidade do paciente certificar-se sobre as ações em saúde às quais está sendo submetido. É parte do empoderamento do paciente certificar-se a respeito do que sabe ou o que deve saber sobre as ações de saúde às quais será submetido. Contudo, a maior parte dos pacientes desconhece seus direitos e os que conhecem, muitas vezes, não são compreendidos pelos profissionais da saúde. (MINISTÉRIO DA SAÚDE, 2014). Enfim, o paciente é uma peça fundamental quando se trata de segurança. Envolvê-lo nesse processo é uma tarefa que precisa ser bem elaborada para que ocorra de forma correta e eficiente. Essa discussão norteia a pergunta de pesquisa: como o paciente pode buscar a sua própria segurança com autonomia nos serviços de saúde?

\section{OBJETIVO:}

Conhecer a produção científica em torno da autonomia do paciente quanto a sua própria segurança nos serviços de saúde.

\section{METODOLOGIA}

Este trabalho trata-se de uma revisão integrativa de literatura. Atenderam aos requisitos desta pesquisa seis artigos entre 2015 e 2018, sendo que estavam disponíveis apenas artigos em inglês.

"Participação do Paciente" and "segurança do paciente"

Bases de dados:

MEDLINE+ LILACS

329 artigos

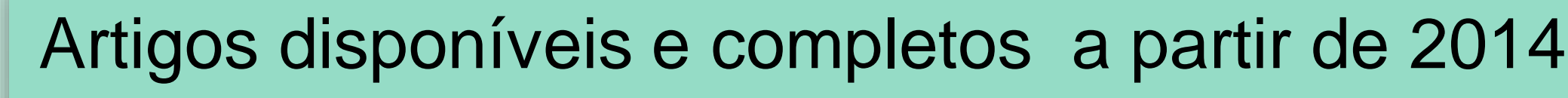

36 artigos

Artigos que atenderam a questão de pesquisa

6 artigos

\section{RESULTADOS}

\begin{tabular}{|l|l|c|}
\hline \multicolumn{1}{|c|}{ Título } & \multicolumn{1}{c|}{ Periódico } & Ano \\
\hline $\begin{array}{l}\text { Family involvement, patient engagement } \\
\text { and benefits of patient education } \\
\text { interventions. }\end{array}$ & $\begin{array}{l}\text { Patient Education and } \\
\text { Conseling }\end{array}$ & 2018 \\
\hline $\begin{array}{l}\text { Evaluation of patient and family } \\
\text { engagament strategies to improve } \\
\text { medication safety. }\end{array}$ & The Patient & 2018 \\
\hline $\begin{array}{l}\text { Patient involvement in patient safety: a } \\
\text { qualitative study of nursing staff and } \\
\text { perceptions. }\end{array}$ & Journal of Patient Safety & 2017 \\
\hline $\begin{array}{l}\text { Patients' perspectives of engagament as } \\
\text { safety strategy. }\end{array}$ & Oncol Nurs Forum & 2017 \\
\hline \begin{tabular}{l} 
Defining the user role in infection control. \\
\hline $\begin{array}{l}\text { Patient participation in medication safety } \\
\text { during an acute care admission. }\end{array}$
\end{tabular} & Journal of Hospital Infection & 2016 \\
\hline
\end{tabular}

Esses artigos tratam da participação ativa do paciente no processo de cuidado com a sua própria segurança. De forma geral, eles enaltecem a importância dessa participação para a melhoria da qualidade dos serviços de saúde, como um componente facilitador do cuidado.

\section{CONCLUSÃO}

O estímulo à participação ativa do paciente no cuidado à saúde é uma ferramenta muito útil para alcançar as Metas de Segurança do Paciente propostas pela ONU e aprimorar atenção à saúde. Além disso, a literatura destaca a importância da atuação em conjunto da instituição e profissionais de saúde e do paciente para a correta informação, atuação e implementação de ações que garantem uma melhor qualidade do cuidado. É certo que ainda são encontradas dificuldades e muito ainda pode ser feito. Contudo, com um paciente participante e entendedor das medidas de segurança pelas quais ele mesmo é responsável, o ele próprio desenvolve maior autonomia para cuidar da sua própria saúde adequadamente. Visto a importância deste tema e os benefícios que pode trazer, é necessário que novas pesquisas sejam feitas e mais formas de preparar a equipe de saúde e o paciente para a autonomia deste sejam desenvolvidas.

\section{REFERÊNCIAS}

BRASIL. Ministério da Saúde. Fundação Oswaldo Cruz; Agência Nacional de Vigilância Sanitária Documento de referência para o Programa Nacional de Segurança do Paciente, 2014

ORGANIZAÇÃO MUNDIAL DE SAÚDE. World Alliance for Patient Safety. First Global Patient Safety Challenge: Clean Care is Safer Care. Genebra; 2006.

ARNSTEIN, F. Family involvement, patient engagement and benefits of patient education interventions. Patient Education and Conseling, 2018.

$\mathrm{KIN}$, J. M. et al. Evaluation of patient and family engagament strategies to improve medication safety. The Patient, 2018.

BISHOP, A.; MACDONALD, M. Patient involvement in patient safety: a qualitative study of nursing staff and perceptions. Journal of Patient Safety, 2017.

BUEEOWS, C.; DUTHIE, E. A. Patients' perspectives of engagament as safety strategy. Oncol Nurs Forum, 2017

AHMAD, R. et al. Defining the user role in infection control. Journal of Hospital Infection, 2016

MCTIER, L. BOTTI, M.Patient participation in medication safety during an acute care admission. Health Expectations, 2015. 